\title{
Assessment of Potential Abatement provided by Annona Muricata (Prickly Custard Apple Leave) on the Toxic Effects of Aluminium Chloride on Albino Rats \\ ${ }^{* 1}$ PROSPER OPUTE; MURICE E. IMIUWA; ONWUKA IFY TAIYE; PREKEYI TAWARI-FUFEYIN
}

\author{
Department of Animal and Environmental Biology, Faculty of Life Sciences, University of Benin, \\ Benin City, Nigeria \\ ${ }^{2}$ Maurice E. Imiuwa, maurice.eghosa@uniben.edu, +2348028945470, ${ }^{3}$ Onwuka Ify Taiye, \\ faithworld4@gmail.com, +234-8024699688, ${ }^{4}$ Prekeyi Tawari-Fufeyin, \\ prekeyi@uniben.edu, +234-8037081237
}

KEY WORDS: Rattus norvegicus, Aluminium Chroride, Annona muricata.

\begin{abstract}
The toxic effects of aluminium Chloride $\left(\mathrm{AlCl}_{3}\right)$ in albino rats (Rattus norvegicus) have been studied. The species weighing $250 \pm 20 \mathrm{~g}$ were administered varying concentrations of the $\mathrm{LD}_{50}\left(3630 \mathrm{mg} / \mathrm{kg}\right.$ body weight), $1 / 2 \mathrm{LD}_{50}(1815 \mathrm{mg} / \mathrm{kg}$ body weight $)$ and $1 / 4$ $\mathrm{LD}_{50}(907.5 \mathrm{mg} / \mathrm{kg}$ body weight) of aluminium Chloride solution orally as drinking water for six weeks after which it was discontinued. The specimens were grouped into three. The first group was administered the various concentrations of $\left(\mathrm{AlCl}_{3}\right)$ with no abatement, while the second and third groups were administered the same concentrations of $\left(\mathrm{AlCl}_{3}\right)$ as the former but were fed respectively with $20 \%$ and $50 \%$ by weight of aqueous leaf extract of Annona muricata mixed with their feeds for six weeks as abatement. Blood samples were collected for biochemical analysis. The results showed significant increase in the levels of urea, creatine, aspartate aminotransferase (AAT), alkaline phosphatase (ALP), alanine aminotransferase (ALAT), total glyceride, total bilirubin, total cholesterol and glucose levels $(\mathrm{P}<0.05)$. However, significant decrease in the levels of these parameters was observed with the application of A. muricata. This reveals the potency of A. muricata leaves to abate the effects of the poison in the kidney and liver of mammals. ( JASEM
\end{abstract}

\section{http://dx.doi.org/10.4314/jasem.v18i1.5}

Introduction: Aluminium, the third most abundant element of the earth's crust, is a non-essential element. It occurs naturally and makes up about $8 \%$ of the surface of the earth (Nayak, 2002). The ubiquity of numerous aluminium compounds in the soil, water and air ensure that we live in an aluminium-rich environment (Nayak, 2002; Molley et al., 2007). Due to its abundance, every organism contains small of the tissues of mammals, including the blood, brain, liver, lung, kidney, heart and bones (Golub et al., 2000; Gonzalez et al., 2007).

Over time, aluminium-contaminated water and other liquids percolate through landfills; the percolating liquid often reacts with the solid waste in the landfill, and may pose public and environmental health risks because of the contaminants it absorbs; Drinking water provide about $1 \%$ of the normal daily aluminium intake (Yokel et al., 2002).
There is little doubt that in the experimental setting, aluminium is toxic to hundreds of cellular processes both in man and animals (Exley and Korchazhkina, (2001). Aluminium intoxication has been reported to cause oxidative stress and a decrease in the intracellular levels of glutathione (Gonzalez et al., 2007). Aluminium might exert its toxic effects by using transport proteins which control iron homeostasis for example, using transport proteins such as tranferrin, or interfering with iron homeostasis at the level of iron regulatory proteins.

Annona muricata Linn. (Annonaceae) is commonly known as 'Soursop' or 'Graviola'. Because of the 'custard-like texture' of its edible fruit, Annona muricata has been grouped with the 'Custard-Apple' plants of the Annonaceae family. It is a deciduous, terrestrial, erect tree of 5-8 metres in height, with an open, roundish canopy. Although a native of America, Annona muricata has now naturalized and

*Corresponding Author: ashibudike.opute@uniben.edu, +2348033644134 
become established in many tropical countries of the world. The plant has been used medicinally in many tropical African countries for an array of human ailments, especially for parasitic infections and cancer. Several chemical compounds have been isolated from various morphological parts (roots, stem-barks, leaves, fruits, and seeds) of Annona muricata Linn. Some of the reported phytochemicals isolated and characterized from various parts of the plant include: annonaceous acetogenins, lactones and isoquinoline alkaloids (TDRG, 2002).

\section{MATERIALS AND METHODS}

Ethical consideration: Experimental protocols and procedures used in this study conform to the position statement and guidelines regarding the use of animals in toxicology by Ethics and research committee of the University of Benin, Benin City, Nigeria. Approval was given by the committee before the commencement of the research work.

Animals: Forty-eight (48) healthy albino Norway rats (Rattus norvegicus) of approximately the same weight $(250 \pm 20 \mathrm{~g})$ were obtained and housed in four cages which were labeled $\mathrm{K}, \mathrm{A}, \mathrm{B}$ and $\mathrm{C}$, each of which housed twelve (12) albino Norway rats. The test animals in cage $\mathrm{K}$ served as control.

The animals were given free access to food (standard rat pellets) and drinking tap water ad libitum for a period of two weeks prior to the start of the experiment. At the end of the acclimatization period, their weights were again taken using a digital electronic weighing balance before the experiment commenced. Group K served as control and were fed with the normal feed and clean portable water. Group A rats were fed with normal feed along with solution A containing $\mathrm{LD}_{50}(3630 \mathrm{mg} / \mathrm{kg}$ body weight $)$ of aluminium chloride as drinking water. Group B and $\mathrm{C}$ were fed with $1 / 2 \mathrm{LD}_{50}(1815 \mathrm{mg} / \mathrm{kg}$ body weight) and $1 / 4 \mathrm{LD}_{50}(907.5 \mathrm{mg} / \mathrm{kg}$ body weight $)$ of aluminium chloride respectively as drinking water. At the end of six weeks which marked the end of the first phase of the experiment, blood samples were collected from the albino rats for biochemical analysis. The administration of aluminium chloride ended with this first phase. The rats in each of cages $\mathrm{A}, \mathrm{B}$, and $\mathrm{C}$ were further divided into three groups $\left(A_{1}-A_{3}, B_{1}-B_{3}\right.$, $C_{1}-C_{3}$ ). Rats in groups $A_{1}, B_{1}, C_{1}$ were fed with normal feed and water without abatement till the end of the second phase of the experiment. Rats in groups $\mathrm{A}_{2}, \mathrm{~B}_{2}$, and $\mathrm{C}_{2}$ were fed with the abatement feed consisting of the normal feed mixed with $20 \%$ by weight of Annona muricata leaves, while rats in groups $\mathrm{A}_{3}, \mathrm{~B}_{3}$, and $\mathrm{C}_{3}$ were fed with normal feed mixed with $50 \%$ by weight of Annona muricata leaves as abatement till the end of second phase of the experiment.

Plant material: Fresh leaves of Annona muricata (Linn.) (family: Annonaceae) (locally known as "Prickly custard apple" in English, and "Abo" in Yoruba language of Western Nigeria) were collected in Ile-Ife, Western Nigeria. The leaves were identified by the Taxonomist/Curator of the Department of Plant Biology and Biotechnology, University of Benin, Benin City, Nigeria, as those of Annona muricata.

Preparation of Annona muricataleaf aqueous extract: A. muricata fresh leaves were air-dried at room temperature. One kilogram $(1 \mathrm{~kg})$ of the airdried leaves of the plant was milled into fine powder in a Warring commercial blender. The powdered leaf was macerated in distilled water and extracted twice, on each occasion with 2.5 1itre of distilled water at room temperature for $48 \mathrm{~h}$ (with occasional shaking). The combined aqueous extract solubles were concentrated to dryness under reduced pressure at $60 \pm 1^{\circ} \mathrm{C}$ in a rotary evaporator. The resulting aqueous extract was freeze-dried, finally yielding $36.23 \mathrm{~g}$ of a light green, powdery crude aqueous leaf extract of $A$. muricata. Without any further purification, the crude aqueous extract thus obtained was refrigerated and subsequently used in this study. Aliquot portions of the crude plant extract residue were weighed and dissolved in distilled water for use on each day of our experiments.

Collection And Analysis Of Blood Samples: Blood samples were collected from the albino rats using disposable sterile syringes and transferred into sterile bottles containing heparin and fluoride oxalate (anticoagulant). The samples were quickly transferred to the chemical pathology laboratory of the University of Benin Teaching Hospital (UBTH) for biochemical analysis. The blood samples collected was centrifuged at $1800 \mathrm{rpm}$ to separate blood serum from the whole blood. The blood serum was used to analyze for the following: Total bilirubin, conjugated bilirubin, ALAT (alanine aminotransferace), ALP (alkaline phosphate), AAT (aspartate aminotranferace), urea, creatinine, glucose and electrolytes $\left(\mathrm{Na}^{+}, \mathrm{K}^{+}, \mathrm{Cl}^{-}\right.$and $\left.\mathrm{HCO}_{3}^{-}\right)$.

Data Analysis: One-way analysis of variance was performed to determine significant differences between treatments and significant effects were accepted at $p<0.05$. Statistical computations were done using SPSS for Windows (version 15.0 SPSS $®$, Chicago, USA). 


\section{RESULTS AND DISCUSSION}

Results obtained from the biochemical analysis showed increase in urea and creatinine levels which were statistically significant $(\mathrm{p}<0.05)$. There was no significant deviation from control in hydrogen carbonate level. Decrease in the levels of electrolytes $\left(\mathrm{Na}^{+}, \mathrm{Cl}^{-}\right.$, and $\mathrm{K}^{+}$) was also recorded (A-C). There was a correlation between the changes observed and the concentrations of aluminium chloride as shown in table 1 . There was no significant difference in values of the parameters after the administration of the metal salt was discontinued for six weeks $\left(\mathrm{A}_{1}-\mathrm{C}_{1}\right)$. With the administration of $20 \%$ and $50 \%$ Annona muricata leaves, lower levels of creatinine and urea was observed $\left(A_{2}-C_{2}\right.$ and $\left.A_{3}-C_{3}\right)$ as shown in table 2 . Other parameters showed no significant difference. The elevation of blood urea is a good indicator of kidney disorder. Urea is the principal end product of protein catabolism. Thus enhanced protein catabolism and accelerated amino acid deamination for gluconeogenesis is possibly an acceptable postulate to interpret the elevated levels of urea (Gross et al., 2005). Elevated creatinine concentration is associated with the abnormal renal function especially as it relates to glomerular function (Gross et al., 2005). The increase of serum urea and creatinine concentration can be a consequence of critical accumulation of this metal in kidneys and thus renal failure development. However, the reduction in the level of serum urea and creatinine levels reveals the potency of Annona muricata leaves to abate the effects of the poison on the kidney. This could be attributed to the antioxidants present in Annona muricata (Adewole and Caxton-Martins, 2006).

Increase in ALP, ALAT, AAT and total bilirubin levels with respect to increase in concentration of the metal salt was observed in the first six weeks of administration. However, there was a decrease in levels of dense bilirubin as shown in table 3 . With the discontinuation of the poisoning for the following six weeks, AAT, ALP, ALAT and biliribin levels were lowered. AAT, ALAT and ALP had lower values compared to the initial poisoned state with the administration of Annona muricata leaves both at $20 \%$ and $50 \%$ weight. The liver cell enzymes are normally found in circulation in small amounts because of hepatic growth and repair. Increase in total bilirubin, ALP, AAT and ALAT can occur in connection with hyperlipidermia, or increased activity of the liver (Patiak, 2002; Al-Hashem, 2009). Thus the reduced values of total bilirubin, ALAT and AAT is an indication of the ability of Annona muricata leaves to abate the damaging effects of Aluminium chloride on the liver. Increase in total cholesterol, total glyceride and decrease in lipoprotein was observed after six weeks of administration of aluminium chloride salt as shown in table 5. After the administration of the poison was discontinued, total cholesterol and total glyceride values were reduced. With the administration of $20 \%$ and $50 \%$ Annona muricata leaves, there was decrease in lipoprotein, total glyceride and cholesterol levels when compared to their initial poisoned state. Glycerides in the form of triglyceride make up most of the fats digested by animals. In the animal body, high levels of triglycerides in the bloodstream have been linked to atherosclerosis. Also, the elevation of cholesterol is a risk factor for coronary heart disease (Morgan, 1995). Again, the reduction in the elevated levels of high dense lipoprotein, total glyceride and total cholesterol after the administration of dried leaves of Annona muricata is an indication of its ability to abate the effects of the metal poisoning.

There was significant increase in glucose levels with the administration of the metal poison as shown in table 7. The values remained high with the discontinuation of the poison. However there was progressive decrease with the administration of Annona muricata leaves. Glucose is a very important energy yielding component. However, abnormally high levels cause health problems. (Chinoy et al., 2004), reported that aluminum chloride caused significant enhancement in the level of glycogen in liver. Reduction in serum glucose level with the administration of Annona muricata leaves is again an indication of its potency to abate the effects of the poisoning on the liver.

Conclusion:Based on our findings, we conclude that exposure to aluminium results to significant increase in the levels of urea, creatinine, ALAT, AAT, ALP, total glyceride, total bilirubin, total cholesterol and total glucose levels. These findings are conclusive of the toxic effects of aluminium and aluminium containing products. Again, A. muricata leaf aqueous extract possesses antioxidant activity which is able to inhibit the effects of metal toxicity. Therefore, extracts from various morphological parts of Annona

muricata can be used medicinally for the control and/or treatment of humans or/and animals exposed to metal poisoning.

Acknowledgments: The authors are grateful to Professor L. Ezemonye, Professor C.E. Okaka, Professor J.O.

Olomukoro and Dr. M.O. Omoigberale for their technical assistance. This research received no specific grant from any funding agency in the public, commercial or nonprofit organizations. 
Table 1. Progressive changes in the kidney function parameters of rats ranging from control to the administration of aluminium chloride solution and discontinuity of poisoning.

\begin{tabular}{l|lllllll}
\hline $\begin{array}{l}\text { Kidney function } \\
\text { parameters }\end{array}$ & Control & $\boldsymbol{A}$ & $\boldsymbol{B}$ & $\boldsymbol{C}$ & $\boldsymbol{A}_{\boldsymbol{I}}$ & $\boldsymbol{B}_{\boldsymbol{I}}$ & $\boldsymbol{C}_{\boldsymbol{I}}$ \\
\hline Urea(mg/dl) & $35( \pm 0.5)$ & $55( \pm 0.5)$ & $53( \pm 0.5)$ & $50( \pm 0.5)$ & $55( \pm 0.5)$ & $52( \pm 0.5)$ & $49( \pm 0.5)$ \\
Creatinine(mg/dl) & $3( \pm 0.2)$ & $12( \pm 0.2)$ & $9( \pm 0.2)$ & $8( \pm 0.2)$ & $10( \pm 0.2)$ & $8( \pm 0.2)$ & $8( \pm 0.2)$ \\
Sodium $(\mathrm{mg} / \mathrm{dl})$ & $126( \pm 0.5)$ & $117( \pm 0.5)$ & $123( \pm 0.5)$ & $127( \pm 0.5)$ & $140( \pm 0.5)$ & $141( \pm 0.5)$ & $141( \pm 0.5)$ \\
Potassium(mg/dl) & $18.4( \pm 0.1)$ & $16.7( \pm 0.1)$ & $15.6( \pm 0.1)$ & $15.2( \pm 0.1)$ & $10.4( \pm 0.1)$ & $11.6( \pm 0.1)$ & $14.3( \pm 0.1)$ \\
Hydrogen $(\mathrm{mg} / \mathrm{dl})$ & $19( \pm 0.2)$ & $18( \pm 0.2)$ & $19( \pm 0.2)$ & $20( \pm 0.2)$ & $14( \pm 0.2)$ & $17( \pm 0.2)$ & $17( \pm 0.2)$ \\
Carbonate (mg/l) & $113( \pm 0.5)$ & $60( \pm 0.5)$ & $58( \pm 0.5)$ & $65( \pm 0.5)$ & $97( \pm 0.5)$ & $97( \pm 0.5)$ & $99( \pm 0.5)$ \\
\hline
\end{tabular}

Table 2. Progressive changes in the kidney function parameters of rats ranging from control to the administration of $20 \%$ and $50 \%$ abatement.

\begin{tabular}{|c|c|c|c|c|c|c|c|}
\hline $\begin{array}{l}\text { Kidney function } \\
\text { parameters }\end{array}$ & Control & $A_{2}$ & $\overline{B_{2}}$ & $C_{2}$ & $A_{3}$ & $\boldsymbol{B}_{3}$ & $C_{3}$ \\
\hline Urea(mg/dl) & $35( \pm 0.5)$ & $48( \pm 0.5)$ & $46( \pm 0.5)$ & $40( \pm 0.5)$ & $39( \pm 0.5)$ & $42( \pm 0.5)$ & $36 \quad( \pm 0.5)$ \\
\hline Creatinine $(\mathrm{mg} / \mathrm{dl})$ & $3( \pm 0.2)$ & $8( \pm 0.2)$ & $6( \pm 0.2)$ & $5( \pm 0.2)$ & $6( \pm 0.2)$ & $4( \pm 0.2)$ & $( \pm 0.2)$ \\
\hline Sodium (mg/dl) & $126( \pm 0.5)$ & $132( \pm 0.5)$ & $131( \pm 0.5)$ & $134( \pm 0.5)$ & $128( \pm 0.5)$ & $125( \pm 0.5)$ & $127( \pm 0.5)$ \\
\hline Potassium (mg/dl) & $18.4( \pm 0.1)$ & $14.2( \pm 0.1)$ & $14.4( \pm 0.1)$ & $16.2( \pm 0.1)$ & $10.7( \pm 0.1)$ & $15.4( \pm 0.1)$ & $17.7( \pm 0.1)$ \\
\hline Hydrogen (mg/dl) & $19( \pm 0.2)$ & $18( \pm 0.2)$ & $17( \pm 0.2)$ & $20( \pm 0.2)$ & $15( \pm 0.2)$ & $15( \pm 0.2)$ & $16 \quad( \pm 0.2)$ \\
\hline Carbonate $(\mathrm{mg} / \mathrm{l})$ & $113( \pm 0.5)$ & $107( \pm 0.5)$ & $105( \pm 0.5)$ & $77( \pm 0.5)$ & $97( \pm 0.5)$ & $97( \pm 0.5)$ & $102( \pm 0.5)$ \\
\hline
\end{tabular}

Table 3. Progressive changes in the liver function parameters of rats ranging from control to the administration of aluminium chloride solution and discontinuity of poisoning.

\begin{tabular}{l|lllllll}
\hline Liver-function parameters & Control & $\boldsymbol{A}$ & $\boldsymbol{B}$ & $\boldsymbol{C}$ & $\boldsymbol{A}_{\boldsymbol{I}}$ & $\boldsymbol{B}_{\boldsymbol{I}}$ & $\boldsymbol{C}_{\boldsymbol{l}}$ \\
\hline AAT $(\mathrm{mg} / \mathrm{dl})$ & $61( \pm 0.5)$ & $90( \pm 0.5)$ & $88( \pm 0.5)$ & $80( \pm 0.5)$ & $89( \pm 0.5)$ & $86( \pm 0.5)$ & $80( \pm 0.5)$ \\
ALAT $(\mathrm{mg} / \mathrm{dl})$ & $28( \pm 0.2)$ & $50( \pm 0.2)$ & $45( \pm 0.2)$ & $41( \pm 0.2)$ & $50( \pm 0.2)$ & $44( \pm 0.2)$ & $40( \pm 0.2)$ \\
ALP $(\mathrm{mg} / \mathrm{dl})$ & $13( \pm 0.1)$ & $53( \pm 0.1)$ & $45( \pm 0.1)$ & $50( \pm 0.1)$ & $10( \pm 0.1)$ & $16( \pm 0.1)$ & $18( \pm 0.1)$ \\
Total bilirubin(mg/dl) & $4( \pm 0.5)$ & $14( \pm 0.5)$ & $9( \pm 0.5)$ & $7( \pm 0.5)$ & $13( \pm 0.5)$ & $9( \pm 0.5)$ & $8( \pm 0.5)$ \\
Dense bilirubin(mg/dl) & $4( \pm 0.1)$ & $3( \pm 0.1)$ & $1( \pm 0.1)$ & $1( \pm 0.1)$ & $2( \pm 0.1)$ & $1( \pm 0.1)$ & $3( \pm 0.1)$ \\
\hline
\end{tabular}

Table 4. Progressive changes in the liver function parameters of rats ranging from control to the administration of $20 \%$ and $50 \%$ abatement.

\begin{tabular}{l|llllllll}
\hline Liver-function parameters & Control & $\boldsymbol{A}_{\mathbf{2}}$ & $\boldsymbol{B}_{2}$ & $\boldsymbol{C}_{\mathbf{2}}$ & $\boldsymbol{A}_{\mathbf{3}}$ & $\boldsymbol{B}_{\mathbf{3}}$ & $\boldsymbol{C}_{\boldsymbol{3}}$ \\
\hline AAT $(\mathrm{mg} / \mathrm{dl})$ & $61( \pm 0.5)$ & $78( \pm 0.5)$ & $72( \pm 0.5)$ & $68( \pm 0.5)$ & $69( \pm 0.5)$ & $68( \pm 0.5)$ & $64( \pm 0.5)$ \\
ALAT $(\mathrm{mg} / \mathrm{dl})$ & $28( \pm 0.2)$ & $45( \pm 0.2)$ & $39( \pm 0.2)$ & $36( \pm 0.2)$ & $35( \pm 0.2)$ & $30( \pm 0.2)$ & $29( \pm 0.2)$ \\
ALP $(\mathrm{mg} / \mathrm{dl})$ & $13( \pm 0.1)$ & $14( \pm 0.1)$ & $16( \pm 0.1)$ & $18( \pm 0.1)$ & $16( \pm 0.1)$ & $18( \pm 0.1)$ & $20( \pm 0.1)$ \\
Total bilirubin(mg/dl) & $4( \pm 0.5)$ & $9( \pm 0.5)$ & $7( \pm 0.5)$ & $7( \pm 0.5)$ & $6( \pm 0.5)$ & $5( \pm 0.5)$ & 4 & $( \pm 0.5)$ \\
Dense bilirubin(mg/dl) & $4( \pm 0.1)$ & $1( \pm 0.1)$ & $2( \pm 0.1)$ & $2( \pm 0.1)$ & $2( \pm 0.1)$ & $1( \pm 0.1)$ & 1 & $( \pm 0.1)$ \\
\hline
\end{tabular}

Table 5. Progressive changes in the lipid profile parameters of rats ranging from control to the administration of aluminium chloride solution and discontinuity of poisoning.

\begin{tabular}{|c|c|c|c|c|c|c|c|}
\hline Lipid-profile parameters & Control & $\boldsymbol{A}$ & $\boldsymbol{B}$ & $C$ & $\boldsymbol{A}_{1}$ & $B_{1}$ & $C_{1}$ \\
\hline Total cholesterol(mg/dl) & $28( \pm 0.5)$ & $54( \pm 0.5)$ & $48( \pm 0.5)$ & $40( \pm 0.5)$ & $54( \pm 0.5)$ & $47( \pm 0.5)$ & $39( \pm 0.5)$ \\
\hline Total glyceride(mg/dl) & $65( \pm 0.5)$ & $79( \pm 0.5)$ & $70( \pm 0.5)$ & $65( \pm 0.5)$ & $77( \pm 0.5)$ & $70( \pm 0.5)$ & $65( \pm 0.5)$ \\
\hline Low-dense lipoprotein(mg/dl) & $14( \pm 0.2)$ & $16( \pm 0.2)$ & $12( \pm 0.2)$ & $14( \pm 0.2)$ & $16( \pm 0.2)$ & $12( \pm 0.2)$ & $14( \pm 0.2)$ \\
\hline $\begin{array}{l}\text { High-dense } \\
(\mathrm{mg} / \mathrm{dl})\end{array}$ & $32( \pm 0.1)$ & $22( \pm 0.1)$ & $23( \pm 0.1)$ & $19( \pm 0.1)$ & $30( \pm 0.1)$ & $28( \pm 0.1)$ & $26( \pm 0.1)$ \\
\hline
\end{tabular}

Table 6. Progressive changes in the lipid profile parameters of rats ranging from control to the administration of $20 \%$ and $50 \%$ abatement.

\begin{tabular}{|c|c|c|c|c|c|c|c|c|}
\hline Lipid-profile parameters & Control & $A_{2}$ & $\boldsymbol{B}_{2}$ & $C_{2}$ & $A_{3}$ & $\boldsymbol{B}_{3}$ & $C_{3}$ & \\
\hline Total cholesterol(mg/dl) & $28( \pm 0.5)$ & $48( \pm 0.5)$ & $39( \pm 0.5)$ & $34( \pm 0.5)$ & $36( \pm 0.5)$ & $30( \pm 0.5)$ & 28 & $( \pm 0.5)$ \\
\hline Total glyceride $(\mathrm{mg} / \mathrm{dl})$ & $65( \pm 0.5)$ & $60( \pm 0.5)$ & $57( \pm 0.5)$ & $54( \pm 0.5)$ & $55( \pm 0.5)$ & $51( \pm 0.5)$ & 50 & $( \pm 0.5)$ \\
\hline Low-dense lipoprotein(mg/dl) & $14( \pm 0.2)$ & $18( \pm 0.2)$ & $14( \pm 0.2)$ & $11( \pm 0.2)$ & $16( \pm 0.2)$ & $18( \pm 0.2)$ & 16 & $( \pm 0.2)$ \\
\hline $\begin{array}{l}\text { High-dense } \\
\text { (mg/dl) }\end{array}$ & $32( \pm 0.1)$ & $30( \pm 0.1)$ & $28( \pm 0.1)$ & $26( \pm 0.1)$ & $28( \pm 0.1)$ & $29( \pm 0.1)$ & 24 & $( \pm 0.1)$ \\
\hline
\end{tabular}


Table 7. Progressive changes in the glucose levels of rats ranging from control to the administration of aluminium chloride solution and discontinuity of poisoning.

\begin{tabular}{l|lllllll}
\hline Glucose level & Control & $\boldsymbol{A}$ & $\boldsymbol{B}$ & $\boldsymbol{C}$ & $\boldsymbol{A}_{\boldsymbol{I}}$ & $\boldsymbol{B}_{\boldsymbol{I}}$ & $\boldsymbol{C}_{\boldsymbol{I}}$ \\
\hline Glucose $(\mathrm{mg} / \mathrm{dl})$ & $28( \pm 2.0)$ & $101( \pm 2.0)$ & $89( \pm 2.0)$ & $79( \pm 2.0)$ & $98( \pm 2.0)$ & $88( \pm 2.0)$ & $78( \pm 2.0)$ \\
\hline
\end{tabular}

Table 8. Progressive changes in the glucose levels of rats ranging from control to the administration of $20 \%$ and $50 \%$ abatement.

\begin{tabular}{l|llllllll}
\hline Glucose level & Control & $\boldsymbol{A}_{2}$ & $\boldsymbol{B}_{2}$ & $\boldsymbol{C}_{2}$ & $\boldsymbol{A}_{3}$ & $\boldsymbol{B}_{3}$ & $\boldsymbol{C}_{3}$ \\
\hline Glucose $(\mathrm{mg} / \mathrm{dl})$ & $28( \pm 2.0)$ & $80( \pm 2.0)$ & $78( \pm 2.0)$ & $67( \pm 2.0)$ & $52( \pm 2.0)$ & $43( \pm 2.0)$ & 38 & $( \pm 2.0)$ \\
\hline
\end{tabular}

\section{REFERENCES}

Adewole, S.O. and Caxton-Martins, E.A. (2006). Morphological changes and hypoglycaemic effects of Annona muricata Linn. (Annonaceae) leaf aqueous extract on pancreatic B-cells of streptozotocin-treated diabetic rats. Journal of Biochemical Research. 6: 173-181

Al-Hasheem, F. (2009). Camel's milk protects against aluminium in Saudi children. Biometals. 9:385-392.

Chinoy, N.J., Sharma, A.K. and Patel, T.N. (2004). Recovery from fluoride and aluminium induced free radical liver toxicity in mice. Fluoride 37(4):257-263

Exley, C. and Korchazhkina, O.V. (2001). Promotion of formation of amyloid fibrils by aluminium adenosine triphosphate (AIATP). Journal of inorganic Biochemistry. 84:215-224

Gonzalez-Munoz, M.J., Mesenguer, I., SanchezReus, M.I. (2007). Beer consumption reduces cerebral oxidation caused by aluminium toxicity by normalizing gene expression of tumor necrotic factor alpha and several antioxidant enzymes. Food Chem. Toxicol.46(3):1111-1118.
Gross, J.L., de Azevedo M.J., Silveiro S.P., Canani L.H., Caramori M.L. and Zelmanovitz, T. (2005)."Diabetic nephropathy: diagnosis, prevention, and treatment". Diabetes Care.28(1):164-176.

Molley, D.W., Standish, T.I. and Nieboer, E. (2007). Effects of acute exposure to aluminium on cognition in humans. J. Toxicol. Environ. Health A. 70(23):2011-2019

Morgan, M. (1995). The significance of ethnicity for health promotion: patient's use of antihypertensive drugs in inner London. Int. J. Epidemiol. 83(1):25-29

Nayak, P. (2002). Aluminium: Impacts and disease. Environ. Res. 89(2):101-115

Patlak, M. (2002). "New weapons to combat an ancient disease: treating diabetes". FASEB $J$. 16(14): 1850-1853

Technical Data Report on Graviola (TDRG), author Annona muricata. Sage Press, Inc.; 2002.

Yokel, R.A., Wilson, M. and Harris, W.R. (2002). Aluminium citrate uptake by immortalized brain endothelial cells: Implications for its blood-brain barrier transport. Brain res. 930(1-2):101-110 